\title{
Proton pump inhibitor alone vs proton pump inhibitor plus mucosal protective agents for endoscopic submucosal dissection-induced ulcer: a systematic review and meta-analysis
}

\author{
Toshihiro Nishizawa, ${ }^{1,2}$ Hidekazu Suzuki, ${ }^{2, *}$ Takanori Kanai ${ }^{2}$ and Naohisa Yahagi ${ }^{1}$ \\ ${ }^{1}$ Division of Research and Development for Minimally Invasive Treatment, Cancer Center and ${ }^{2}$ Division of Gastroenterology and Hepatology, \\ Department of Internal Medicine, Keio University School of Medicine, 35 Shinanomachi, Shinjuku-ku, Tokyo 160-8582, Japan
}

(Received 15 August, 2014; Accepted 26 August, 2014; Published online 27 December, 2014)

\begin{abstract}
Mucosal protective agents may improve healing of patients with endoscopic submucosal dissection-induced ulcers. The present study systematically evaluated published clinical trials to determine whether combined therapeutic use of mucosal protective agents and proton pump inhibitors can improve the outcome of patients with endoscopic submucosal dissection-induced ulcers compared to treatment with proton pump inhibitors alone. PubMed, the Cochrane Library, and the Igaku-Chuo-Zasshi database were searched to identify eligible randomized trials for systematic review. We identified 11 randomized trials for inclusion in our study (1,160 patients). Pooled endoscopic submucosal dissectioninduced ulcer healing rates were $45.8 \%$ and $34.4 \%$ for patients with or without mucosal protective agents, respectively. The odds ratio was 2.28 (95\% confidence interval, 1.57-3.31) with no significant study heterogeneity. In conclusion, the systematic review and meta-analysis showed that the combined therapeutic use of proton pump inhibitors and mucosal protective agents improved healing rates of endoscopic submucosal dissection-induced ulcers compared to treatment with proton pump inhibitor monotherapy.
\end{abstract}

Key Words: mucosal protective agents, endoscopic submucosal dissection, ulcer, rebamipide

E ndoscopic submucosal dissection (ESD) is recently developed technique that has made endoscopic resection of large gastric lesions possible. ${ }^{(1)}$ A recent study showed that proton pump inhibitors (PPIs) more effectively prevented bleeding due to ESDinduced gastric ulcers than histamine $\mathrm{H}_{2}$-receptor antagonists. ${ }^{(2)}$ Mucosal protective agents developed in Japan have been used for the treatment of upper gastrointestinal ulcers. The generally assumed mechanism underlying the action of these agents involves the up-regulation of gastric mucosal defenses during recovery of mucosal tissue. Mucosal protective agents include drugs such as rebamipide, ecabet sodium, polaprezinc, sucralfate, sodium alginate, plaunotol, sofalcone, teprenone, irsogladine maleate, misoprostol, and aluminum-magnesium hydroxide, which are widely prescribed, in East Asia. ${ }^{(3,4)}$

A meta-analysis study recently demonstrated that treatment of ESD-induced ulcers with PPIs plus rebamipide results in superior outcomes to PPI monotherapy. ${ }^{(5)}$ The healing rates of ESDinduced ulcers might be improved by not only rebamipide but also other mucosal protective agents. Several studies have also examined the efficacy of other mucosal protective agents with PPI for the treatment of ESD-induced ulcers. Our objective was to perform a systematic review and meta-analysis of published randomized controlled trials (RCTs) in order to evaluate the efficacy of treatment with PPI plus mucosal protective agents.

\section{Methods}

Before performing the meta-analysis, we developed a protocol that included search strategies, criteria for study selection, the method of extraction of related data, methods for assessing study quality, and statistical methodology.

Search strategy. The electronic databases PubMed, the Cochrane Library, and the Igaku-Chuo-Zasshi in Japan (from 1950 to June 2014) were used to systematically search the literature for a combination of the following words: (endoscopic submucosal dissection OR ESD) AND (mucosal protective agents, mucosal defensive agents, rebamipide, ecabet sodium, polaprezinc, sucralfate, alginate, plaunotol, sofalcone, teprenone, irsogladine, misoprostol, OR aluminum-magnesium). Articles published in any language were included. Although abstracts occasionally include less information and may possess less accuracy, we retrieved them to reduce publication bias; in essence, studies with negative results are less likely to reach full publication.

Inclusion and exclusion criteria. Articles were considered eligible if the studies met the following inclusion criteria: (1) study type: RCTs; (2) population: patients who had undergone ESD; (3) intervention: an active treatment with PPI plus mucosal protective agents; (4) comparison group: treatment with PPI monotherapy; (5) outcome: reported healing rates of ESD-induced ulcers. The major exclusion criteria were: (1) a non-RCT; (2) administration of rebamipide in the control group; (3) no ulcer healing rates reported; or (4) duplicate publications, case reports and reviews.

Data extraction. Standardized data abstraction sheets were prepared. Data were extracted for study quality, endoscopic therapy use, medication duration, patient follow-up time, and sex and age of enrolled subjects. Key outcome data were abstracted from all included studies. All articles were examined independently for eligibility by two reviewers (T.N. and H.S.). Disagreements were resolved by consulting a third reviewer (N.Y.).

Outcome measures. The primary outcome measured was healing rates of ESD-induced ulcers. The ulcer stage was classified using the classification of Sakita and Miwa: active (A1 and A2), healing ( $\mathrm{H} 1$ and $\mathrm{H} 2)$, and scaring (S1 and S2). ${ }^{(6)}$ S-stage was defined as the healing of an artificial ulcer. The secondary outcome measured was safety, which was analyzed by evaluating complication rates.

*To whom correspondence should be addressed. E-mail: hsuzuki@a6.keio.jp 
Assessment of methodological quality. The methodological quality of each study was assessed using the risk-of-bias tool outlined in the Cochrane Handbook for Systematic Reviews of Interventions (ver. 5.1.0). Two reviewers (T.N. and H.S.) reviewed all studies and assessed 6 key aspects influencing quality of an RCT, including sequence generation, allocation concealment, blinding of both participants and outcome assessors, management of eventual incomplete outcome data, completeness of outcome reporting, and other potential threats to validity.

Statistical analysis. Data were entered into StatsDirect statistical software. The odds ratios (ORs) were calculated for ulcer healing rates with PPI plus mucosal protective agents were compared to that with PPI monotherapy. We used a random-effect model to calculate summary ORs and $95 \%$ confidence intervals (CIs). Heterogeneity between the studies was assessed using Cochrane's Q and I-Squared test. Because of the low power of the $\mathrm{Q}$ test, a cut-off value $<0.10$ was used to reject homogeneity, indicating heterogeneity. An I-squared score $\geq 50 \%$ indicated more than moderate heterogeneity. ${ }^{(7)}$ The subgroup analyses were performed for each individual mucosal protective agent that allowed the groups to be classified into patients who had received four- and eight-week treatments. To evaluate the statistical stability of this meta-analysis, we performed a sensitivity analysis to evaluate the effect of low-quality studies (conference abstracts). Finally, we used funnel plot asymmetry to detect any publication bias in the meta-analysis, and Egger's regression test to measure funnel plot asymmetry.

\section{Results}

Literature search. Our database search yielded 109 citations (Fig. 1). After adjusting for duplicates, 63 studies remained. Of these, 37 studies were removed from consideration after reviewing the abstracts, based on exclusion criteria (20 unrelated topics, 5 reviews, 4 case reports, and 8 animal studies). The remaining 26 studies were examined in detail. Studies were then excluded due to lack of randomization $(n=6)$, control groups $(n=7)$, or reported ulcer healing rates $\left(n=2\right.$ conference abstracts) ${ }^{(8,9)}$ Finally, 11 studies ( 8 full papers and 3 conference abstracts) were included in the systematic review and meta-analysis. ${ }^{(10-20)}$

Characteristics and quality of eligible studies. The characteristics of the 11 studies are summarized in Table 1. The risk of bias in the RCTs is shown in Table 2. In general, the 8 full paper

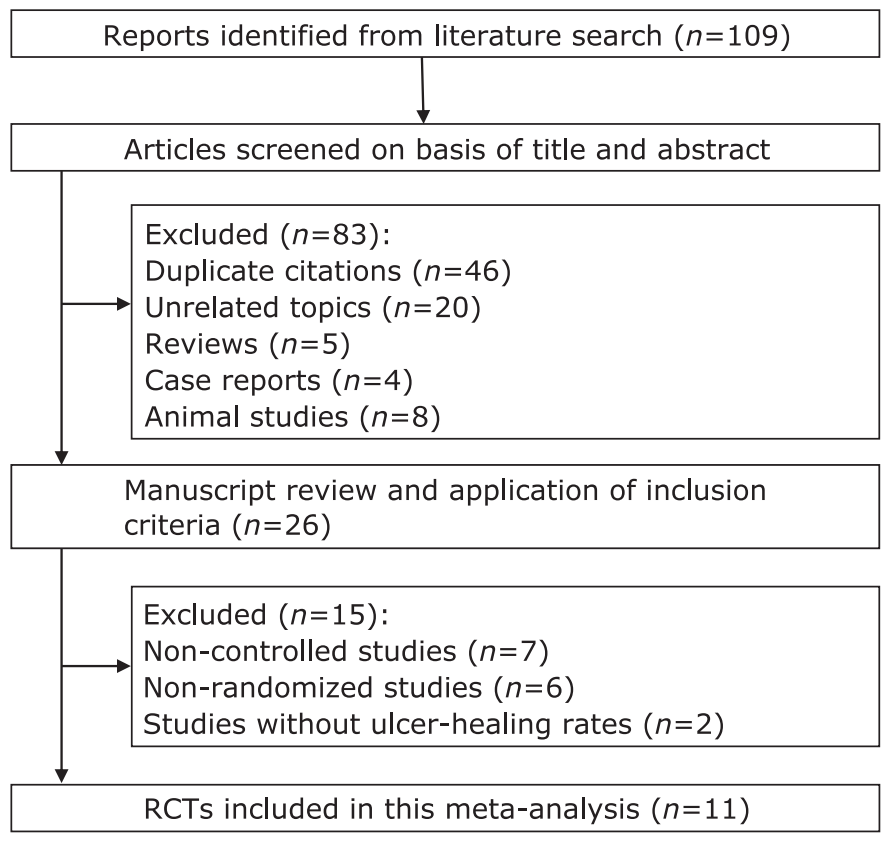

Fig. 1. Flow chart for selecting RCTs for inclusion in the systematic review.

Table 1. Characteristics of studies included in the meta-analysis

\begin{tabular}{|c|c|c|c|c|c|}
\hline $\begin{array}{l}\text { Author } \\
\text { Year }\end{array}$ & Country & $\begin{array}{l}\text { Mucosal protective } \\
\text { agents }\end{array}$ & $\begin{array}{l}\text { Patients } \\
\text { number }\end{array}$ & Intervention & $\begin{array}{c}\text { Duration } \\
\text { (days) }\end{array}$ \\
\hline $\begin{array}{l}\text { Kato } \\
2010\end{array}$ & Japan & Rebamipide & 31 & $\mathrm{RPZ}+$ rebamipide $300 \mathrm{mg} /$ day & 28 \\
\hline $\begin{array}{l}\text { Fujiwara } \\
2011\end{array}$ & Japan & Rebamipide & 30 & OPZ + rebamipide $300 \mathrm{mg} / \mathrm{day}$ & 56 \\
\hline \multirow{2}{*}{$\begin{array}{l}\text { Araki } \\
2012\end{array}$} & \multirow{2}{*}{ Japan } & \multirow{2}{*}{ Rebamipide } & 42 & OPZ 20 mg/day, LPZ 30 mg/day or RPZ 10 mg/day & \multirow{2}{*}{28} \\
\hline & & & 45 & $\mathrm{PPI}+$ rebamipide $300 \mathrm{mg} /$ day & \\
\hline $\begin{array}{l}\text { Kobayashi } \\
2012\end{array}$ & Japan & Rebamipide & 85 & $\mathrm{PPI}+$ rebamipide $300 \mathrm{mg} /$ day & $28-42$ \\
\hline \multirow{2}{*}{$\begin{array}{l}\text { Shin } \\
2012\end{array}$} & \multirow{2}{*}{ Korea } & \multirow{2}{*}{ Rebamipide } & 129 & Pantprazole 40 mg/day & \multirow{2}{*}{28} \\
\hline & & & 126 & Pantprazole + rebamipide $300 \mathrm{mg} /$ day & \\
\hline \multirow{2}{*}{$\begin{array}{l}\text { Takayama } \\
2013\end{array}$} & \multirow{2}{*}{ Japan } & \multirow{2}{*}{ Rebamipide } & 44 & LPZ 30 mg/day & \multirow{2}{*}{$28 / 56$} \\
\hline & & & 45 & LPZ $30 \mathrm{mg} /$ day, 5 days; then rebamipide $300 \mathrm{mg} /$ day & \\
\hline $\begin{array}{l}\text { Asakuma } \\
2009\end{array}$ & Japan & Ecabet & 27 & RPZ 20 mg/day & $28 / 56$ \\
\hline \multirow{2}{*}{$\begin{array}{l}\text { Inaba } \\
2010\end{array}$} & \multirow{2}{*}{ Japan } & \multirow{2}{*}{ Polaprezinc } & 80 & LPZ 30 mg/day & 56 \\
\hline & & & 79 & LPZ + polaprezinc $150 \mathrm{mg} /$ day & 56 \\
\hline Yoshida & lanan & Polanrezinc & 27 & OPZ 20 mg/day & 56 \\
\hline 2013 & Japan & Polaprezınc & 23 & OPZ + polaprezinc $150 \mathrm{mg} / \mathrm{day}$ & 56 \\
\hline Miyahara & lanan & Irsogaladine & 45 & PPI & 28 \\
\hline 2013 & Japan & Irsogladıne & 51 & PPI + irsogladine & 28 \\
\hline
\end{tabular}

RPZ: rabeprazole, OPZ: omeprazole, LPZ: lansoprazole. 
Table 2. Evaluation of bias of RCTs included in the meta-analysis

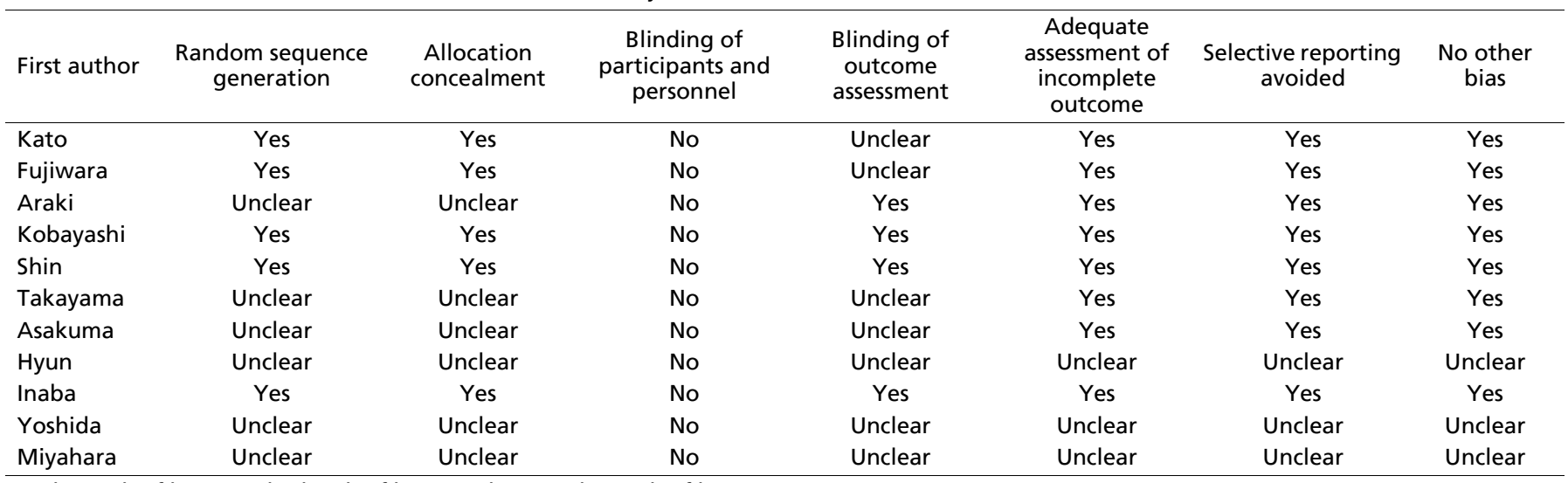

Yes: low risk of bias, No: high risk of bias, Unclear: unclear risk of bias.

\begin{tabular}{|c|c|c|c|c|c|c|}
\hline \multirow[t]{2}{*}{ Description } & \multicolumn{2}{|c|}{$\begin{array}{c}\text { PPI+mucosal } \\
\text { protective agents }\end{array}$} & PPI alone & \multicolumn{2}{|c|}{$\begin{array}{l}\text { Odds ratio meta-analysis plot } \\
\text { (random effects, } 95 \% \text { confidence interval) }\end{array}$} & \multirow[t]{2}{*}{$\begin{array}{l}\text { Odds ratio } \\
(95 \% \mathrm{CI})\end{array}$} \\
\hline & & $n / N$ & $n / N$ & & & \\
\hline Kato 2010 & Rebamipide & $21 / 31$ & $11 / 31$ & & 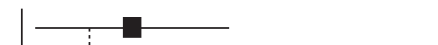 & $3.82(1.19,12.53)$ \\
\hline Fujiwara 2011 & Rebamipide & $26 / 30$ & $17 / 31$ & & $=$ & $5.35(1.34,25.46)$ \\
\hline Araki 2012 & Rebamipide & $20 / 45$ & $6 / 42$ & & 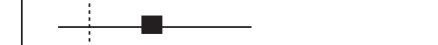 & $4.80(1.55,16.47)$ \\
\hline Kobayashi 2012 & Rebamipide & $16 / 85$ & $13 / 85$ & & & $1.28(0.53,3.13)$ \\
\hline Shin 2012 & Rebamipide & $33 / 126$ & $20 / 129$ & & & $1.93(1.00,3.81)$ \\
\hline Takayama 2013 & Rebamipide & $15 / 45$ & $12 / 44$ & & & $1.33(0.49,3.67)$ \\
\hline Asakuma 2009 & Ecabet & $11 / 28$ & $3 / 27$ & & - & $5.18(1.10,32.29)$ \\
\hline Hyun 2010 & Ecabet & $15 / 38$ & $14 / 38$ & & & $1.12(0.40,3.13)$ \\
\hline Inaba 2010 & Polaprezinc & $77 / 79$ & $77 / 80$ & & 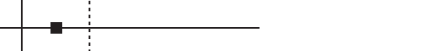 & $1.50(0.17,18.38)$ \\
\hline Yoshida 2013 & Polaprezinc & $22 / 23$ & $24 / 27$ & & & $2.75(0.20,150.81)$ \\
\hline Miyahara 2013 & Irsogladine & $10 / 51$ & $2 / 45$ & & $\square$ & $5.24(1.01,51.29)$ \\
\hline Total & & $266 / 581$ & $199 / 579$ & & & $2.28(1.57,3.31)$ \\
\hline Test for heteroge & neity: $\begin{aligned} X^{2} & =13 \\
I^{2} & =23^{\circ}\end{aligned}$ & $\mathrm{df}=10, p$ & $=0.225$ & $\begin{array}{lll}0.1 & 0.2 & 0.5\end{array}$ & $\begin{array}{ll}1 & 1 \\
5 & 10\end{array}$ & 1,000 \\
\hline
\end{tabular}

Fig. 2. Odds ratio meta-analysis plot comparing ESD-induced ulcer healing rates for patients receiving treatment with PPIs plus mucosal protective agents versus those receiving PPI monotherapy.

studies in the analysis had low risk of bias. The 3 conference abstracts had an unclear risk of bias. Six RCTs ( 3 full papers and 3 abstracts) did not describe the specific methods of random sequence generation and allocation concealment. Methods of blindness assessment were not described for 7 studies (4 full papers and 3 abstracts). The 3 abstracts did not adequately assess incomplete outcomes or how selective outcome reporting was avoided. All 8 full paper studies were free of other biases.

Efficacy analysis. Pooled healing rates were achieved for 266 of 581 patients $(45.8 \%)$ treated with mucosal protective agents and for 199 of 579 patients $(34.4 \%)$ who had not received mucosal protective agents (OR 2.28, 95\% CI 1.57-3.31, $p<0.0001$, Fig. 2). There was no significant heterogeneity among the trial results $\left(\chi^{2}=13.0, p=0.225, \mathrm{I}^{2}=23 \%\right)$. In the subgroup analysis based on duration of treatment, we found that treatment with PPIs plus mucosal protective agents was more effective in healing ESD-induced ulcers than PPI monotherapy over both four-
(OR 2.19, 95\% CI 1.43-3.34, $p=0.0003$, Fig. 3) and eight-week treatments (OR 3.03, 95\% CI 1.42-6.48, $p=0.0043$, Fig. 4).

Additive effects of individual mucosal protective agents were also analyzed (Table 3). Rebamipide and irsogladine were significantly effective, but the study on irsogladine was one of the conference abstracts. Ecabet sodium and polaprezinc were not significantly effective.

Adverse events. Three trials reported adverse events. The study by Fujiwara et al. ${ }^{(11)}$ reported that one patient in the PPI group experienced bleeding due to a post-ESD artificial ulcer. There were no other serious adverse events.

Sensitivity analysis and publication bias. To analyze statistical sensitivity of our meta-analysis, we excluded three lowquality studies (conference abstracts). Exclusion of these studies did not significantly alter the outcome of the meta-analysis. (OR $2.40,95 \%$ CI $1.58-3.65, p<0.0001$, Fig. 5). The funnel plot had almost symmetrical distribution (Fig. 6), and Egger's regression 


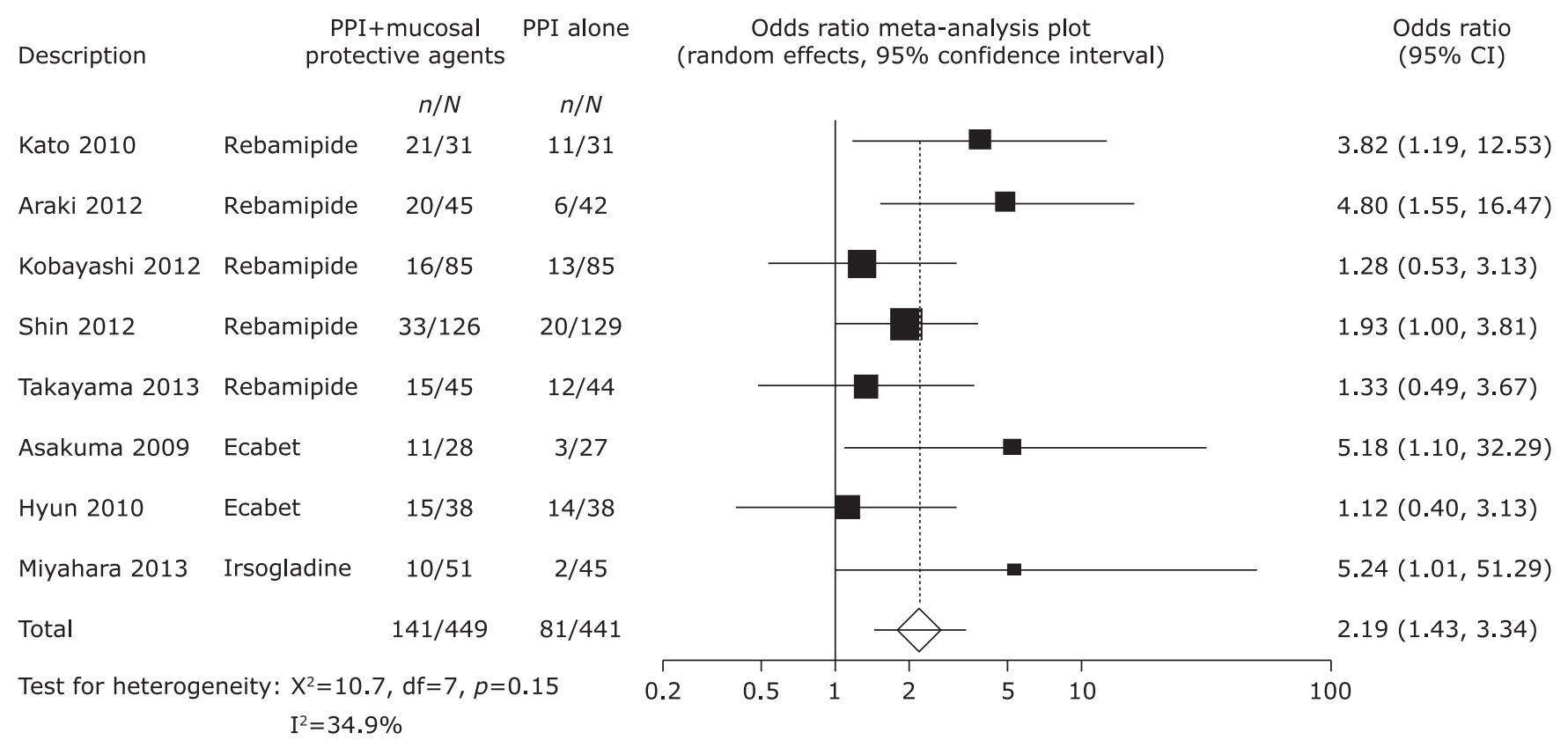

Fig. 3. Odds ratio meta-analysis plot comparing ESD-induced ulcer healing rates in patients treated for 4 weeks with PPIs plus mucosal protective agents versus those receiving PPI monotherapy.

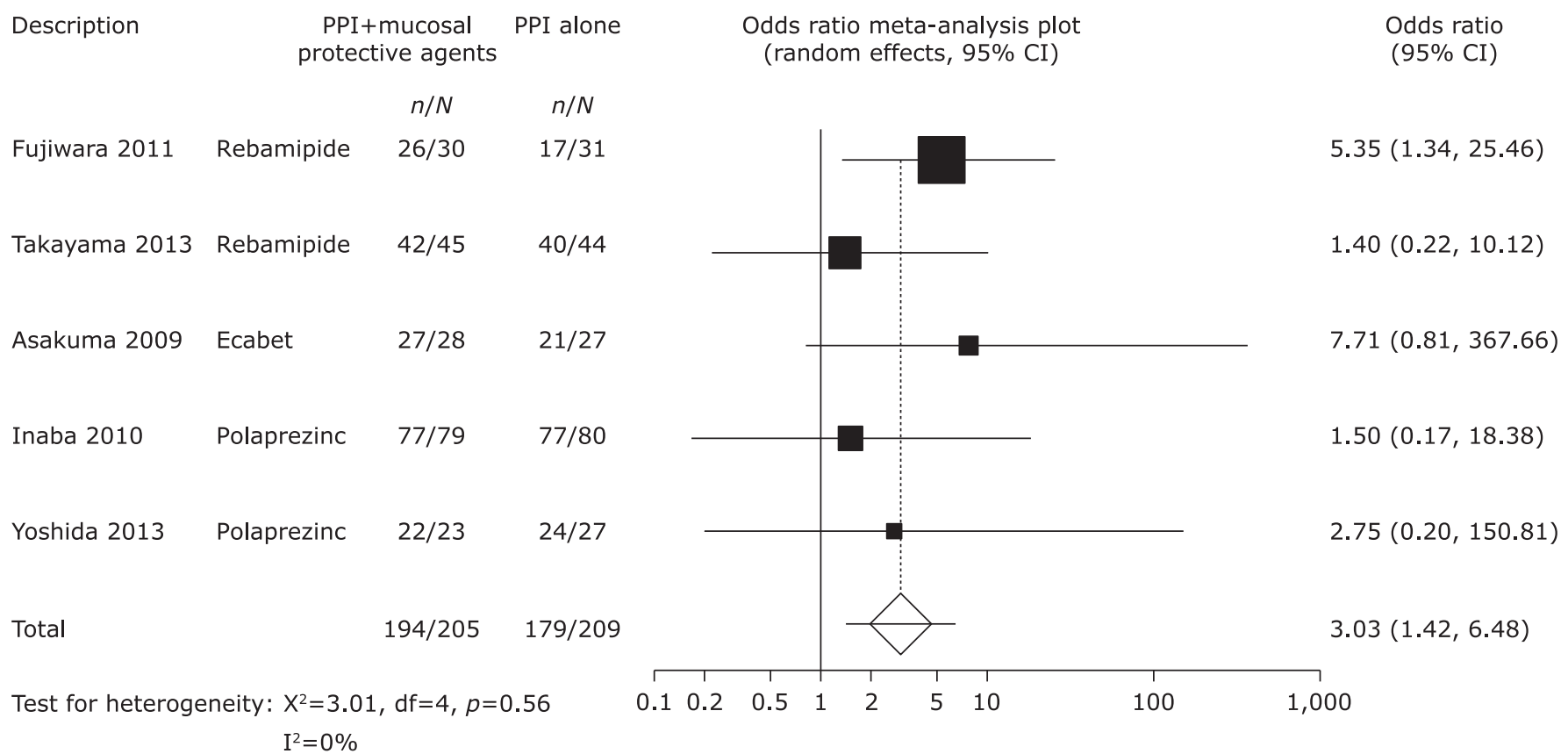

Fig. 4. Odds ratio meta-analysis plot comparing ESD-induced ulcer healing rates in patients treated for 8 weeks with PPIs plus mucosal protective agents versus those receiving PPI monotherapy.

Table 3. Pooled Odds ratio and its $95 \% \mathrm{Cl}$ in the studies of each mucosal protective agent

\begin{tabular}{lccc}
\hline Mucosal protective agent & Odds ratio & $95 \% \mathrm{Cl}$ & $\begin{array}{c}\text { Number of } \\
\text { studies }\end{array}$ \\
\hline Rebamipide & 2.4 & $1.68-3.44$ & 6 \\
Ecabet & 2.18 & $0.49-9.70$ & 2 \\
Polaprezinc & 1.89 & $0.44-7.91$ & 2 \\
Irsogladine & 5.24 & $1.08-25.4$ & 1 \\
\hline
\end{tabular}

test suggested no significant asymmetry of the funnel plot $(p=0.15)$, indicating no evidence of substantial publication bias.

\section{Discussion}

This systematic review and meta-analysis indicated that therapeutic use of PPIs plus mucosal protective agents is superior to PPI monotherapy for ESD-induced ulcers. We therefore expect that mucosal protective agents will become more widely utilized 


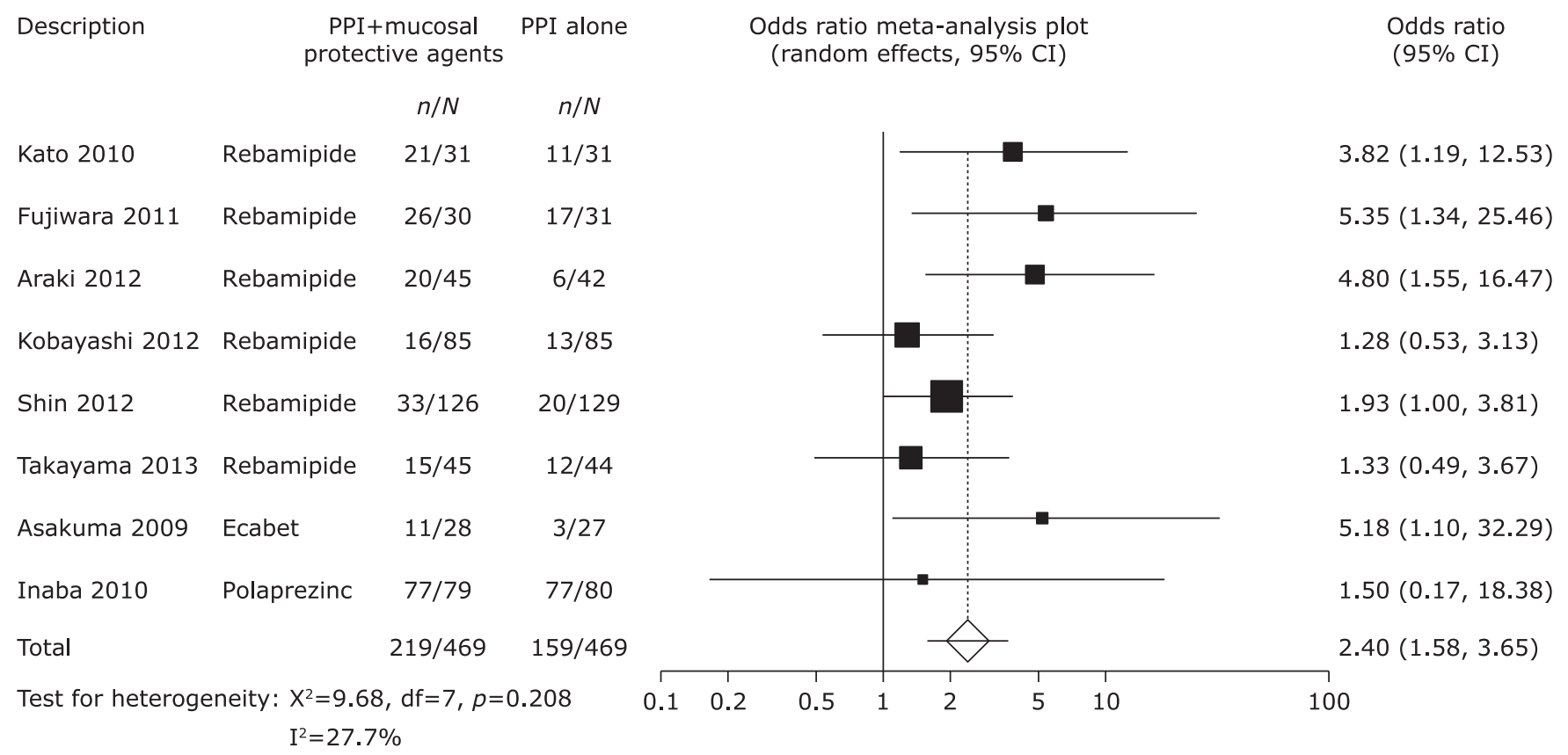

Fig. 5. Odds ratio meta-analysis plot comparing ESD-induced ulcer healing rates in patients treated with PPIs plus mucosal protective agents versus those receiving PPI monotherapy excluding reports from three conference abstracts.

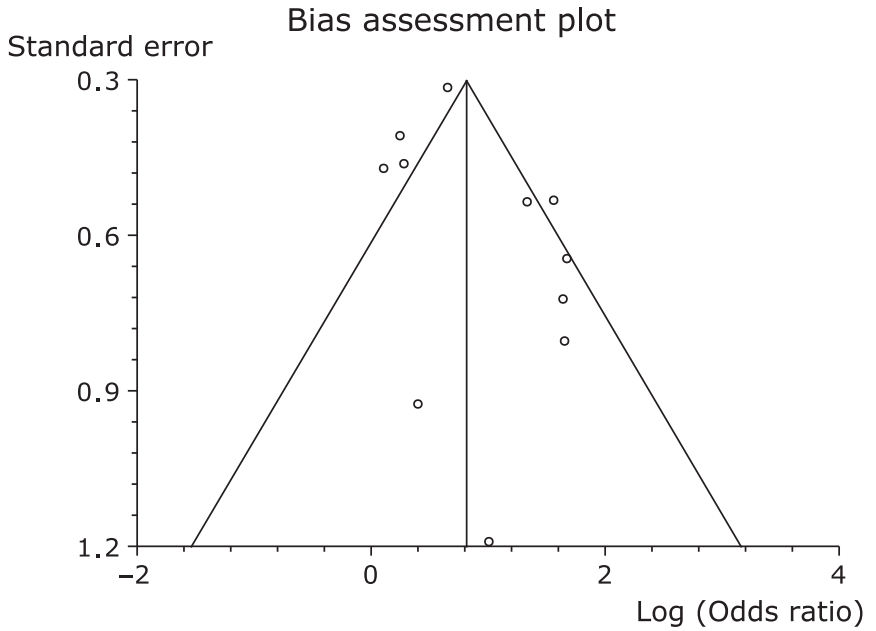

Fig. 6. Funnel plot of the included studies for ESD-induced ulcer healing rates.

for treatment of ESD-induced ulcers.

Mucosal protective agents are safe and widely used as anti-ulcer drugs in East Asia. Rebamipide \{2-(4-chlorobenzoylamino)-3[2(1H)-quinolinon-4-yl] propionic acid; Otsuka Pharmaceutical Co., Ltd., Tokyo, Japan\} exerts a preventive effect on gastric ulcer formation by inhibiting neutrophil activation. ${ }^{(21,22)}$ Rebamipide is an oxygen-radical scavenger, stimulates the generation of cytoprotective prostaglandins, and increases blood flow in the gastric mucosa. ${ }^{(23-25)}$ Ecabet sodium (12-sulfodehydroabietic acid monosodium salt; Mitsubishi Tanabe Pharma Corporation, Osaka, Japan) has protective effects such as endogenous prostaglandins and nitric oxide synthesis and increases blood flow in the gastric mucosa. ${ }^{(26)}$ Ecabet sodium also exhibits a bactericidal effect against Helicobacter pylori by inhibiting bacterial urease activity. ${ }^{(27)}$ Polaprezinc $[N$-(3-amino propionyl)-L-histidine zinc; Zeria Pharmaceutical Co., Ltd., Tokyo, Japan] promotes ulcer healing with actions such as prostaglandin-independent cytoprotection, antioxidant activity, leukocyte inactivation, and membrane stabilization. ${ }^{(28)}$ Moreover, polaprezinc stimulates the production of insulin-like growth factor 1 , thus promoting mucosal wound healing. ${ }^{(29)}$ Irsogladine [2,4-diamino-6-(2,5-dichlorophenyl)s-triazine; Nippon Shinyaku Co., Ltd., Kyoto, Japan] suppresses free radical production, facilitates intercellular communication via gap junctions, and enhances gastric mucosal blood flow. ${ }^{(30)}$ These actions accelerate mucosal or submucosal reconstruction and enhance the quality of ulcer healing.

In clinical practice, it is important to understand which mucosal protective agents are most effective for improving healing of gastric ulcers. Among the drugs analyzed in our study, rebamipide and irsogladine were significantly effective. However, the study on irsogladine was of low quality. Further, it was difficult to evaluate whether Ecabet sodium and polaprezinc were effective because the sample sizes in these studies were not large enough to uncover significant differences. Although rebamipide seems most effective, well-designed trials are needed to confirm these findings.

The costs of rebamipide, ecabet sodium, polaprezinc, and irsogladine for 28 days are $¥ 1,462$, $¥ 1,271, ¥ 2,106$, and $¥ 1,840$, respectively. The costs of rabeprazole $(20 \mathrm{mg} /$ day $)$ and lansoplazole ( $30 \mathrm{mg} /$ day) for 28 days are $¥ 7,448$ and $¥ 4,648$, respectively. The costs of mucosal protective agents are relatively low. Takayama et $a l^{(15)}$ reported that rebamipide monotherapy was equivalent to treatment with a PPI in the healing of ESD-induced ulcers and treatment with rebamipide was more cost-effective than treatment with the PPI. Mucosal protective agents might be able to reduce the costs by reducing the dose of PPI.

The present systematic review and meta-analysis has several limitations that need to be taken into account when interpreting the results. None of the included RCT trials met all quality criteria, which may have influenced the results. In addition, most participants in the studies were Japanese and Korean; therefore, these results may not be generalizable to other races.

In conclusion, our analysis demonstrates that supplementing PPI therapy with mucosal protective agents could improve healing of ESD-induced ulcers. 


\section{Acknowledgments}

This work was supported by Princess Takamatsu Cancer Research grants (to H.S.), a grant from the Smoking Research Foundation (to H.S.), and the Keio Gijuku Academic Development Fund (to H.S.).

\section{Conflict of Interest}

During the last 2 years, Author H.S. received scholarship funds for the research from Astellas Pharm Inc., Astra-Zeneca K.K., Otsuka Pharmaceutical Co., Ltd., Takeda Pharmaceutical Co., Ltd., and Zeria Pharmaceutical Co., Ltd., and received service honoraria from Astellas Pharm Inc., Astra-Zeneca K.K., Eisai Co., Otsuka Pharmaceutical Co., Ltd., Takeda Pharmaceutical Co., Ltd., and Zeria Pharmaceutical Co., Ltd. Author T.K. received scholarship funds for the research from Astellas Pharm Inc.,

\section{References}

1 Yahagi N, Yamamoto H. Endoscopic submucosal dissection for colorectal lesions. Tech Gastrointest Endosc 2013; 15: 96-100.

2 Yang Z, Wu Q, Liu Z, Wu K, Fan D. Proton pump inhibitors versus histamine-2-receptor antagonists for the management of iatrogenic gastric ulcer after endoscopic mucosal resection or endoscopic submucosal dissection: a meta-analysis of randomized trials. Digestion $2011 ; \mathbf{8 4}$ : 315-320.

3 Haruma K, Ito M. Review article: clinical significance of mucosal-protective agents: acid, inflammation, carcinogenesis and rebamipide. Aliment Pharmacol Ther 2003; 18 Suppl 1: 153-159.

4 Terano A, Arakawa T, Sugiyama T, et al. Rebamipide, a gastro-protective and anti-inflammatory drug, promotes gastric ulcer healing following eradication therapy for Helicobacter pylori in a Japanese population: a randomized, double-blind, placebo-controlled trial. J Gastroenterol 2007; 42: 690-693.

5 Wang J, Guo X, Ye C, et al. Efficacy and safety of proton pump inhibitors (PPIs) plus rebamipide for endoscopic submucosal dissection-induced ulcers: a meta-analysis. Intern Med 2014; 53: 1243-1248.

6 Sakita T, Miwa T. Endoscopic diagnosis of malignant ulcer. J Jpn Soc Gastroenterol 1970; 67: 984-989.

7 Nishizawa T, Suzuki H, Matsuzaki J, Kanai T, Yahagi N. Propofol vs traditional sedative agents for endoscopic submucosal dissection: a systematic review. Dig Endosc 2014; 26: 701-706.

8 Sawaguchi M, Horikawa Y, Mizutamari H, et al. Role of mucosal-protective agents, rebamipide and polaprezinc, in post-gastric endoscopic submucosal dissection ulcer healing - a randomized controlled study. Gastrointest Endosc 2011; 73: AB424

9 Imagawa A, Fujiki S, Akaho S, et al. Prospective comparison study for endoscopic submucosal dissection-induced ulcers; PPI 8 weeks vs. PPI 4 weeks then rebamipide 4 weeks vs. PPI 1 week plus rebamipide 8 weeks. Gastroenterol Endosc 2012; 51: 2191.

10 Kato T, Araki H, Onogi F, et al. Clinical trial: rebamipide promotes gastric ulcer healing by proton pump inhibitor after endoscopic submucosal dissection-a randomized controlled study. J Gastroenterol 2010; 45: 285290.

11 Fujiwara S, Morita Y, Toyonaga T, et al. A randomized controlled trial of rebamipide plus rabeprazole for the healing of artificial ulcers after endoscopic submucosal dissection. J Gastroenterol 2011; 46: 595-602.

12 Araki H, Kato T, Onogi F, et al. Combination of proton pump inhibitor and rebamipide, a free radical scavenger, promotes artificial ulcer healing after endoscopic submucosal dissection with dissection size $>40 \mathrm{~mm}$. J Clin Biochem Nutr 2012; 51: 185-188.

13 Kobayashi M, Takeuchi M, Hashimoto S, et al. Contributing factors to gastric ulcer healing after endoscopic submucosal dissection including the promoting effect of rebamipide. Dig Dis Sci 2012; 57: 119-126.

14 Shin WG, Kim SJ, Choi MH, et al. Can rebamipide and proton pump inhibitor combination therapy promote the healing of endoscopic submucosal dissection-induced ulcers? A randomized, prospective, multicenter study. Gastrointest Endosc 2012; 75: 739-747.

15 Takayama M, Matsui S, Kawasaki M, et al. Efficacy of treatment with rebamipide for endoscopic submucosal dissection-induced ulcers. World $J$ Gastroenterol 2013; 19: 5706-5712.

16 Asakuma Y, Kudo M, Matsui S, et al. Comparison of an Ecabet sodium
Astra-Zeneca K.K., Otsuka Pharmaceutical Co., Ltd., Takeda Pharmaceutical Co., Ltd., Eisai Pharmaceutical Co., Ltd., Zeria Pharmaceutical Co., Ltd., Tanabe Mitsubishi Pharmaceutical Co., Ltd., JIMRO Co., Ltd., Kyorin Pharmaceutical Co., Ltd., and received service honoraria from Astellas Pharm Inc., Eisai Pharmaceutical Co., Ltd., JIMRO Co., Ltd., Tanabe Mitsubidhi Pharmaceutical Co., Ltd., Otsuka Pharmaceutical Co., Ltd., Takeda Pharmaceutical Co., Ltd., Miyarisan Pharmaceutical Co., Ltd., and Zeria Pharmaceutical Co., Ltd. Author N.Y. received scholarship funds for the research from Astra-Zeneca K.K., Takeda Pharmaceutical Co., Ltd., Eisai Co., Top Corporation, Kaigen Pharm Co., Ltd., ASKA Pharmaceutical Co., Ltd., FUJIFILM Corporation, Boston Scientific Japan K.K., Century Medical Inc., and Covidien Japan Inc. The funding sources had no role in the design, practice or analysis of this study. There are no other conflicts of interests for this article.

sodium sodium and proton pump inhibitor (PPI) combination therapy with PPI alone in the treatment of endoscopic submucosal dissection (ESD)induced ulcers in early gastric cancer: prospective randomized study. Hepatogastroenterology 2009; 56: 1270-1273.

17 Hyun Y, Hwan C, Kyung B, et al. Comparison of the efficacy of lansoprazole and lansoprazole plus Ecabet sodium sodium sodium in the treatment of iatrogenic gastric ulcers after endoscopic submucosal dissection. Dig Endosc 2010; 22: A45.

18 Inaba $\mathrm{T}$, Ishikawa $\mathrm{S}$, Toyokawa $\mathrm{T}$, et al. Basal protrusion of ulcers induced by endoscopic submucosal dissection (ESD) during treatment with proton pump inhibitors, and the suppressive effects of polaprezinc. Hepatogastroenterology 2010; 57: 678-684.

19 Yoshida N, Tomatsuri N, Terasaki K, et al. Efficacy of combination therapy with polaprezinc plus proton pump inhibitor for gastric ulcer after endoscopic submucosal dissection. J Jpn Soc Gastroenterol 2013; 110: A888.

20 Miyahara R, Funasaka K, Ono E, et al. Efficacy of irsogladine maleate for endoscopic submucosal dissection-induced ulcers. Gastrointest Endosc 2013; 55(Suppl.2): 2764.

21 Suzuki H, Mori M, Kai A, et al. Effect of rebamipide on H. pylori-associated gastric mucosal injury in Mongolian gerbils. Dig Dis Sci 1998; 43(9 Suppl): 181S-187S.

22 Suzuki M, Miura S, Mori M, et al. Rebamipide, a novel antiulcer agent, attenuates Helicobacter pylori induced gastric mucosal cell injury associated with neutrophil derived oxidants. Gut 1994; 35: 1375-1378.

23 Nishizawa T, Suzuki H, Nakagawa I, et al. Rebamipide-promoted restoration of gastric mucosal sonic hedgehog expression after early Helicobacter pylori eradication. Digestion 2009; 79: 259-262.

24 Naito Y, Yoshikawa T. Rebamipide: a gastrointestinal protective drug with pleiotropic activities. Expert Rev Gastroenterol Hepatol 2010; 4: 261-270.

25 Ogasawara N, Sasaki M, Itoh Y, et al. Rebamipide suppresses TLR-TBK1 signaling pathway resulting in regulating IRF3/7 and IFN- $\alpha / \beta$ reduction. $J$ Clin Biochem Nutr 2011; 48: 154-160.

26 Munakata W, Liu Q, Shimoyama T, Sawaya M, Umeda T, Sugawara K. Ecabet sodium sodium sodium attenuates reactive oxygen species produced by neutrophils after priming with bacterial lipopolysaccharides. Luminescence 2003; 18: 330-333.

27 Ito Y, Shibata K, Hongo A, Kinoshita M. Ecabet sodium sodium sodium, a locally acting antiulcer drug, inhibits urease activity of Helicobacter pylori. Eur J Pharmacol 1998; 345: 193-198.

28 Suzuki H, Mori M, Seto K, et al. Polaprezinc attenuates the Helicobacter pylori-induced gastric mucosal leucocyte activation in Mongolian gerbils-a study using intravital videomicroscopy. Aliment Pharmacol Ther 2001; 15: $715-725$.

29 Ueda K, Ueyama T, Oka M, Ito T, Tsuruo Y, Ichinose M. Polaprezinc (Zinc L-carnosine) is a potent inducer of anti-oxidative stress enzyme, heme oxygenase (HO)-1 - a new mechanism of gastric mucosal protection. $J$ Pharmacol Sci 2009; 110: 285-294.

30 Akagi M, Amagase K, Murakami T, Takeuchi K. Irsogladine: overview of the mechanisms of mucosal protective and healing- promoting actions in the gastrointestinal tract. Curr Pharm Des 2013; 19: 106-114. 